\title{
Effect of carbon nanotubes sonication on mechanical properties of cement pastes
}

\section{Avaliação da influência do processo de sonicação de nanotubos de carbono utilizados em pastas cimentícias}

\author{
J. E. L. DE SIQUEIRA \\ joselsiqueira@gmail.com \\ https://orcid.org/0000-0002-4552-5084 \\ P. J. P. GLEIZE a \\ p.gleize@ufsc.br \\ https://orcid.org/0000-0003-4029-9345
}

\begin{abstract}
The excellent mechanical properties of carbon nanotubes (CNTs) make them a highly attractive material for use as reinforcement in cement composites. However, it is established that this nanomaterial presents a severe dispersion problem in cement matrices owing to its high specific surface area. An alternative method for dispersing the CNTs is the use of sonication in the presence of a superplasticizer admixture. However, high energy sonication can severely damage CNTs, which can affect their behavior in cement pastes. Thus, it is necessary to optimize the CNTs sonication parameters to optimize the performance of CNT-cement pastes. After sonication with different energies of CNTs water suspensions, the CNTs dispersion was evaluated through UV-Vis spectroscopy and the eventual CNTs damage observed by TEM. Workability, compressive and flexural strengths of the CNTs-cement pastes were also measured. The results revealed that the sonication parameters can be optimized to enhance the effect of CNTs on cement paste behavior.
\end{abstract}

Keywords: carbon nanotube, sonication, UV-Vis spectroscopy, mechanical strength.

\section{Resumo}

As excepcionais propriedades mecânicas dos nanotubos de carbono (NTC) os tornam um material extremamente atraente para utilização como reforço de compósitos cimentícios. No entanto, sabe-se que esse nanomaterial apresenta grande problema de dispersão em matrizes cimentícias devido a sua elevada superfície específica. Uma das alternativas para dispersar os NTC é a utilização de sonicação em conjunto com aditivo superplastificante. Apesar disso, alta energia de sonicação pode danificar de maneira severa os NTC, o que pode afetar seu comportamento em pastas de cimento. Dessa forma, é necessário otimizar os parâmetros de sonicação a fim de melhorar o desempenho das pastas cimentícias com NTC. Após a sonicação de soluções aquosas de NTC sob diferentes energias, as dispersões foram submetidas a espectroscopia UV-Vis e os eventuais danos sofridos foram obervados por MET. Plasticidade e resistência a compressão e tração de pastas de cimento com NTC também foram medidas. Os resultados revelaram que os parâmetros de sonicação podem ser otimizados a fim de melhorar os efeitos da incorporação de NTC no comportamento de pastas de cimento.

Palavras-chave: nanotubos de carbono, sonicação, espectroscopia UV-Vis, resistência mecânica.

Federal University of Santa Catarina, Civil Engineering Department, Laboratory of Application of Nanotechnology in Civil Construction, Florianopolis, SC, Brazil. 


\section{Introduction}

The continuous pursuit of upgradation in the construction industry demands continuous research for new materials. With respect to this fact, carbon nanotubes (CNTs) can be considered to be new materials with a high potential for incorporation in cement matrices. CNTs exhibit extraordinary mechanical, electrical and therma properties. Its use as a reinforcement material is preferred owing to its high Young's modulus and strength [1].

Several researchers have noticed a significant enhancement in the physical-mechanical properties of cement composites with the incorporation of carbon nanotubes [2-7].

The significant challenge in their use is the understanding of their interaction with the matrix. Owing to their physical and chemical properties, these materials tend to agglutinate, demanding the use of physical and/or chemical processes to provide higher dispersion and the stabilization of such properties in order to prevent reagglomeration [8].

The most common process used for the dispersion of carbon nanotubes is ultra-sonication, which is generally combined with other techniques such as the use of solvents, surfactants, and CNTs covalent and non-covalent functionalization [3]. According to Ma et al. [8], ultra-sonication is a highly efficient method for CNTs dispersion in low-viscosity liquids such as water, acetone and ethanol.

The sonication process is based on the conversion of electric voltage into mechanical vibrations, which are transferred to the liquid environment and result in the formation and collapse of microscopic bubbles. During this process, also known as cavitation, thousands of shockwaves are created and a high level of energy is released, causing the dispersion of nanomaterials in the liquid [3]. According to Chen et al. [9], the sonication of carbon nanotubes can act as forces of separation and of shear. The former separates nanotubes individually from agglomerates of bundles and increase the concentration of CNTs dispersed in the environment by the sonication energy. Simultaneously, the shear forces cut individual nanotubes into several smaller ones, thus reducing the average individual length of the CNTs. The length and concentration distribution of the nanotubes are two inherent factors that can affect the efficiency of their reinforcement in nanocomposites. Therefore, it is important to use optimal sonication energy to balance the effects of the dispersion and length reduction of the CNTs [10].

Ma et al. [8] cautioned that if the sonication is very aggressive (high energy) and/or takes too long, the CNTs are likely to be severely damaged, particularly when a tip sonicator is used. In severe cases, the graphene layers are completely destroyed and there is a drastic reduction in its mechanical properties.

However, it is noteworthy that there is no consensus in the literature regarding the sonication parameters (energy, time, range, etc.) that are more appropriate for the dispersion of CNTs. TABLE 1 presents a few sonication parameters used in several researches. The absence of key parameters necessary to ensure more effectively characterized experiments is apparent.

After sonication of the nanomaterials, it is necessary to examine the quality of the dispersion. There are certain methods to measure the effectiveness of the dispersion method used as well as the degree of dispersion of the CNTs, particularly in the aqueous medium. Few researchers $[10,19,22]$ captured digital images of the suspensions of CNT after using the dispersion method. The suspensions were kept still and the images were recaptured after different periods of time, to verify the occurrence of sedimentation/ re-agglomeration of the nanomaterials.

Another feasible method is UV-Vis (visible-ultraviolet) spectroscopy. Unlike completely dispersed CNTs, CNT bundles are not active in the wavelength range of $200-1200 \mathrm{~nm}$. This demonstrates that there is a relation between the concentration of individual CNTs dispersed in the medium and the intensity of the absorbance corresponding to the spectrum [16, 20, 23-25].

It is noteworthy that higher sonication energies do not result in higher absorbance and, consequently, higher dispersion of CNTs. Isfahani, Li and Redaelli [21] tested functionalized and pristine CNTs and observed that the pristine CNTs can be dispersed until a certain level, beyond which there was no improvement with the increase

Table 1

Parameters of CNTs suspensions sonication in literature (adapted from Carlesso [11])

\begin{tabular}{|c|c|c|c|c|c|}
\hline Authors & Amplitude & $\begin{array}{l}\text { Equipment input } \\
\text { power }(W)\end{array}$ & Duration (min) & Total energy (J) & $\begin{array}{c}\text { Energy/volume } \\
(\mathrm{J} / \mathrm{ml})\end{array}$ \\
\hline$[2]$ & $(x)$ & $(x)$ & 120 & $(x)$ & $(x)$ \\
\hline [9] & $(x)$ & 500 & $140(*)$ & $280000(\#)$ & $(x)$ \\
\hline [10] & $50 \%$ & 500 & $140\left(^{*}\right)$ & $280000(\#)$ & $(x)$ \\
\hline$[12]$ & $(x)$ & $(x)$ & 100 & $840000(\#)$ & 8400(\#) \\
\hline [13] & $20 \%$ and $40 \%$ & 750 & 30 & 13500 to 39600 (\#) & 270 to $1584(\#)$ \\
\hline [14] & $50 \%$ & 500 & $140\left(^{*}\right)$ & $280000(\#)$ & $(x)$ \\
\hline [15] & $70 \%$ & 500 & 20 to 30 & 94368 and $141522(\#)$ & 555 and $833(\#)$ \\
\hline [16] & $70 \%$ & $(x)$ & until 210 & $(x)$ & $(x)$ \\
\hline [17] & $(x)$ & 150 & 12 & $(x)$ & $(x)$ \\
\hline [18] & $20 \%$ & 750 & $360\left(^{*}\right)$ & until 170000 & $(x)$ \\
\hline [19] & $100 \%$ & 500 & 1 to $14\left({ }^{*}\right)$ & 9000 to $126000(\#)$ & 25 to 400 \\
\hline [20] & $100 \%$ & 500 & 1 to $14\left(^{*}\right)$ & 9000 to $126000(\#)$ & 25 to 400 \\
\hline [21] & $(x)$ & $(x)$ & 30,60 and 120 & 126000 to $504000(\#)$ & 1800 to $7200(\#)$ \\
\hline
\end{tabular}


Table 2

Characteristics of the carbon nanotubes

\begin{tabular}{ccccc}
\hline Density $\left(\mathrm{g} / \mathrm{cm}^{3}\right)$ & $\varnothing$ ext $(\mathrm{nm})$ & Length $\left(\mu_{\mathrm{m}}\right)$ & Length/diameter $(\mathrm{l} / \mathrm{d})$ & Purity $(\%)$ \\
\hline $1.5-1.9$ & $8-15$ & $10-50$ & $666-6250$ & 95 \\
\hline
\end{tabular}

in sonication energy. However, the dispersion of the functionalized CNTs was proportional to the increase in the sonication energy. In addition, the mechanical performances of the cement composite were not affected by the incorporation of the sonicated CNTs.

The incorporation of CNTs in cement composites is also likely to affect its workability. Owing to its large specific area, the nanomaterial tends to reduce in consistency and to increase the cohesion of the mixtures $[19,20]$. Thus, it is necessary to use superplasticizer admixtures to maintain adequate workability of the cement compounds, apart from aiding the dispersion of the nanomaterials. This study intends to verify the influence of several sonication parameters on the dispersion and integrity of CNTs, as well as the effects of CNTs on certain properties of cement compounds.

\section{Experimental program}

\subsection{Materials}

The Portland cement used was CP II-F, according to the Brazilian standard NBR-5737 (1992) of Portland cement specification. A sodium-polycarboxylate-based superplasticizer was used as dispersant. The carbon nanotubes were purchased from Cheap Tubes Inc. and used as received. The main characteristics of the CNTs used in this study are presented in TABLE 2 and their morphology is shown in FIGURE 1.

\subsection{Conditions of sonication and dispersion}

The contents of CNTs and superplasticizer were fixed at $0.1 \%$ by weight of the cement content.

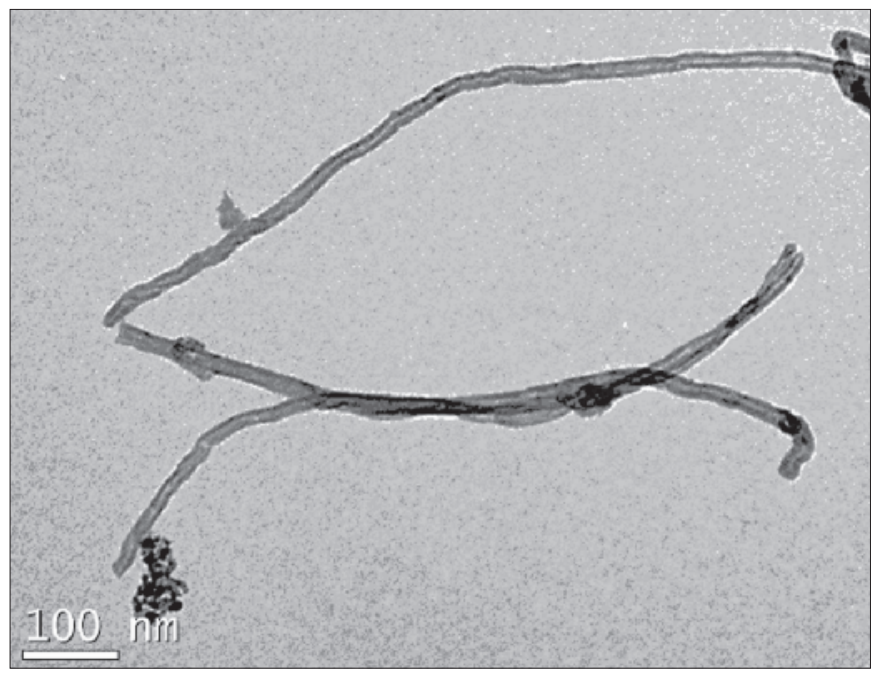

For the dispersion of the CNTs, a tip sonicator model VCX $750 \mathrm{~W}$ (Sonics \& Materials, Inc.) was used. It was equipped with a $13 \mathrm{~mm}$ diameter probe that was dipped into a $30 \mathrm{ml}$ aqueous solution containing CNTs following the recommendations of the manufacturer regarding the processing capability of this probe. The adjustable parameters of sonication in the equipment are the amplitude and duration of operation.

The amplitudes were fixed at two levels: 50 and $80 \%$. The sonication time varied among three values (6,30 and $60 \mathrm{~min}$.) during 20 -second-cycles (on and off) in order to prevent overheating of the CNTs suspension. As recommended by the equipment manufacturer, the power delivered into the liquid was measured as the difference between the amount of watts displayed with the probe immersed into the liquid and the amount of watts displayed with the probe in air (not immersed into the liquid); thus the average applied sonication powers was 27 and $54 \mathrm{~W}$ for the amplitudes 50 and $80 \%$, respectively.

Apart from the variable sonication parameters, the superplasticizer was added at two moments: pre- and post-sonication. This was done in order to verify whether the superplasticizer aided the dispersal of the nanomaterials in the medium during sonication and whether its behavior was affected by the different sonication energies. It is also noteworthy that suspensions without the SP were also sonicated in order to verify whether the sonication process alone was adequate for the dispersion of the CNTs.

The evaluation of the dispersion degree was conducted by UV-Vis spectroscopy, as recommended by [21, 23, 24, 26, 27]. The solution suspension was diluted 30 times and subjected to UV-Vis radiation in glass containers, and the absorbance of the suspension with the CNTs was measured using a spectrometer. According to

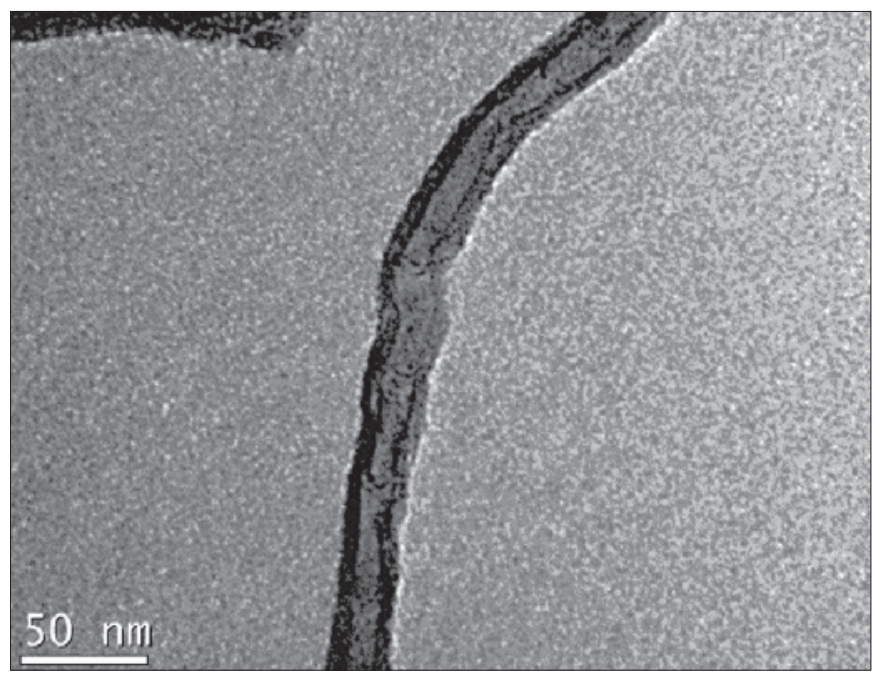

Figure 1

TEM images of the carbon nanotubes 


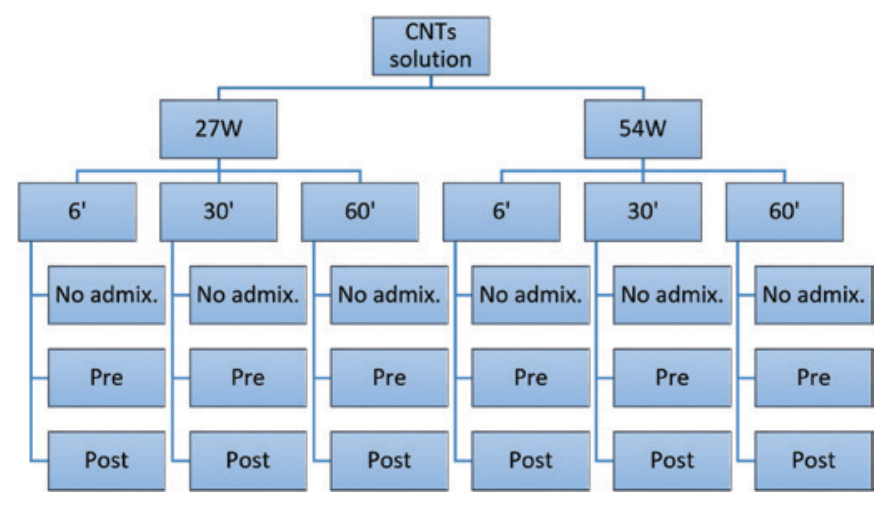

\section{Figure 2}

\section{Organogram of suspensions parameters in} preliminary dispersion study

Zou et al. [20], only nanotubes that are effectively dispersed in the medium can absorb light in the UV-Vis band. The higher the absorbance of the suspension is, the higher the level of dispersion of the nanotubes; therefore, the presence of nanomaterials agglomerates can be estimated and it could indicate a low rate of dispersion. FIGURE 2 shows an organogram of the suspensions parameters. The numbers are related to the power outputs ( 27 and $54 \mathrm{~W}$ ) and the duration (6, 30 or $60 \mathrm{~min})$ of sonication. The terms "Post" and "Pre" refer to whether the admixture was added after or before the sonication process, respectively.

Moreover, TEM observations were performed in order to verify the integrity of the CNTs after sonication.

\subsection{Preparation and tests of cement compounds}

As the purpose of this work is to study the effect of sonication on CNTs dispersion and integrity and its consequences on cement paste performance, a reference cement paste (RP) with no sonication and containing admixture and CNTs was made. Then, other pastes were made with the highest results of CNTs dispersion from the preliminary study, with similar dosage and under the effect of

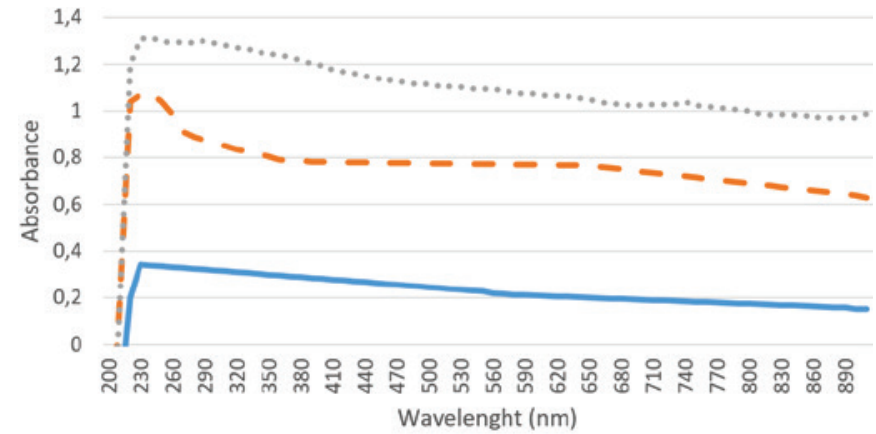$$
{ }^{\text {No admix }}-\text { Post } \cdots \text { P...P Pre }
$$

\section{Figure 3}

UV-Vis absorbance of CNTs suspensions after sonication for 60 min with $80 \%$ amplitude and $6480 \mathrm{~J} / \mathrm{ml}$ the different sonication parameters previously presented. The water/cement ratio was fixed at 0.30 .

Immediately after the sonication process, the cement paste was prepared in a laboratorial mixer for a period of $3 \mathrm{~min}$ at a frequency of $15 \mathrm{~Hz}$ (440 rpm).

The pastes consistencies were measured with mini-slump tests. In this test, a mold with a smaller diameter of $19 \mathrm{~mm}$, larger diameter of $38 \mathrm{~mm}$ and height of $57 \mathrm{~mm}$ was used.

The compressive strength measurements were performed on $20 \times 40 \mathrm{~mm}$ cylindrical specimens. Three-point bending flexural strength tests were carried out on $100 \times 20 \times 20 \mathrm{~mm}$ rectangular specimens. After demolding ( 1 day), the specimens were cured in saturated lime water for 28 days.

\section{Results and discussions}

\subsection{Dispersion and integrity of the carbon nanotubes}

The CNTs dispersion efficiency in the aqueous solution under the sonication processes described in FIGURE 2 and measured by UV-Vis spectroscopy resulted in a set of curves similar to the one presented in FIGURE 3.

It is observed that there is a peak of the curve after a particular band of wavelength. According to George et al. [28], the maximum absorbance value is directly proportional to (and can be an indicative of) the level of dispersion of the CNTs. Therefore, FIGURE 4 shows the maximum absorbance values for all the tested suspensions.

Irrespectively of the sonication conditions, negligible absorbance difference was observed within the CNTs suspensions without the SP admixture. Moreover, the absorbance maxima are significantly lower compared to those of the suspensions with SP. Consequently, it can be concluded that in this case, CNTs dispersion is negligible.

For the suspensions with SP, the absorbance tends to be gradually enhanced according to the increase in energy for the different sonication times. However, no trend was observed in the post-sonication suspensions.

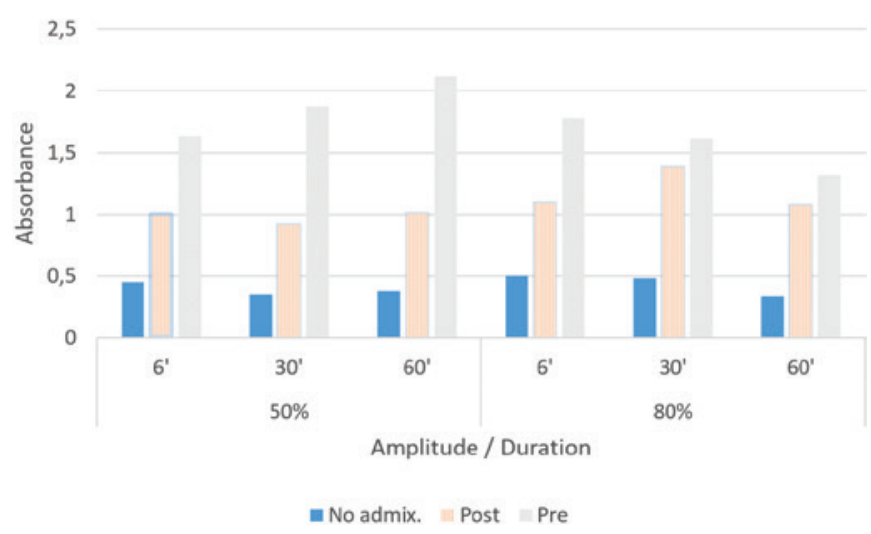

Figure 4

Maximum UV-Vis absorbance of CNTs suspensions after sonication 


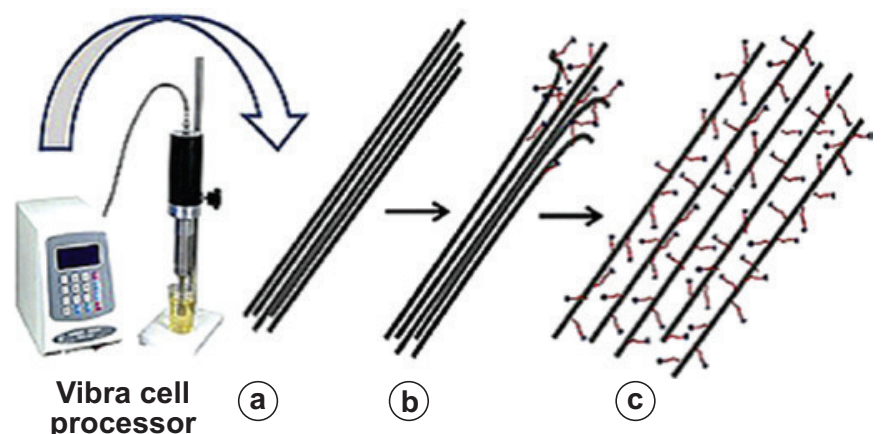

Figure 5

CNTs detachment mechanism with the aid of surfactant and sonication as proposed by Strano et al. [29]

For the suspensions in which the SP is sonicated with the CNTs, at $50 \%$ amplitude, the increase in duration of sonication increases dispersion. For $80 \%$ amplitude, the opposite occurs. Nevertheless, it can be concluded that this is the type of process that exhibits the highest CNTs dispersions.

Strano et al. [29] had proposed a mechanism of the dispersion of CNTs that occurs with the aid of surfactant and sonication (FIGURE 5). According to the authors, the high degree of local shear, particularly on the tips of the CNTs bundles, causes the deviation of the extremities and creates spaces between the layers of nanomaterials, which become points of high adsorption of the surfactant. As the sonication proceeds, the bundles continue to move apart from each other and more surfactant is adsorbed on the surface of the CNTs until their complete separation from the agglomerate. In FIGURE 6, the values of the UV-Vis absorbance maxima correlated with the sonication energy by volume of solution are plotted. With the in-

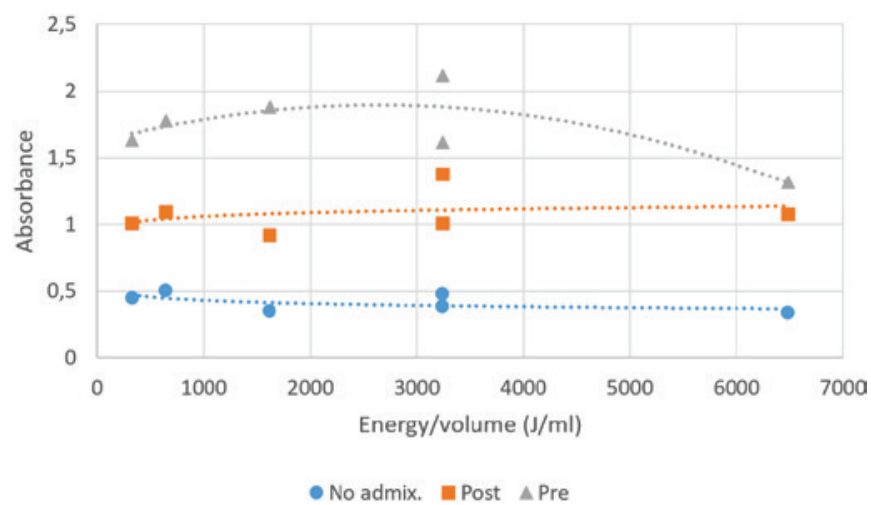

Figure 6

UV-Vis absorbance maxima vs sonication energy of CNTs suspensions

crease in sonication energy, an absorbance plateau for post-sonication suspensions and a trend of a lower absorbance for the pre-sonication suspensions are evident. Zou et al. [20], Isfahani, Li and Redaelli [21], Yu et al. [25] and George et al. [28] also observed this behavior.

FIGURE 7 shows TEM micrographs of the CNTs after (a) $80 \%$ amplitude over $60 \mathrm{~min}(6480 \mathrm{~J} / \mathrm{ml})$ and (b) $50 \%$ amplitude over $30 \mathrm{~min}$ $(1620 \mathrm{~J} / \mathrm{ml})$ sonication. A significant reduction in CNT length as well as the breaking of its wall and consequent reduction in its diameter were observed.

It is assumed that the disintegration and breaking of the CNTs cause the reduction in absorbance verified by UV-Vis spectroscopy. Notwithstanding the higher dispersion caused by the sonication, the quantity of small pieces of CNT available in the solution is likely to increase, which may result in an absorbance decrease due to the higher quantity and possible re-agglomeration of individual nanotubes in the suspension.

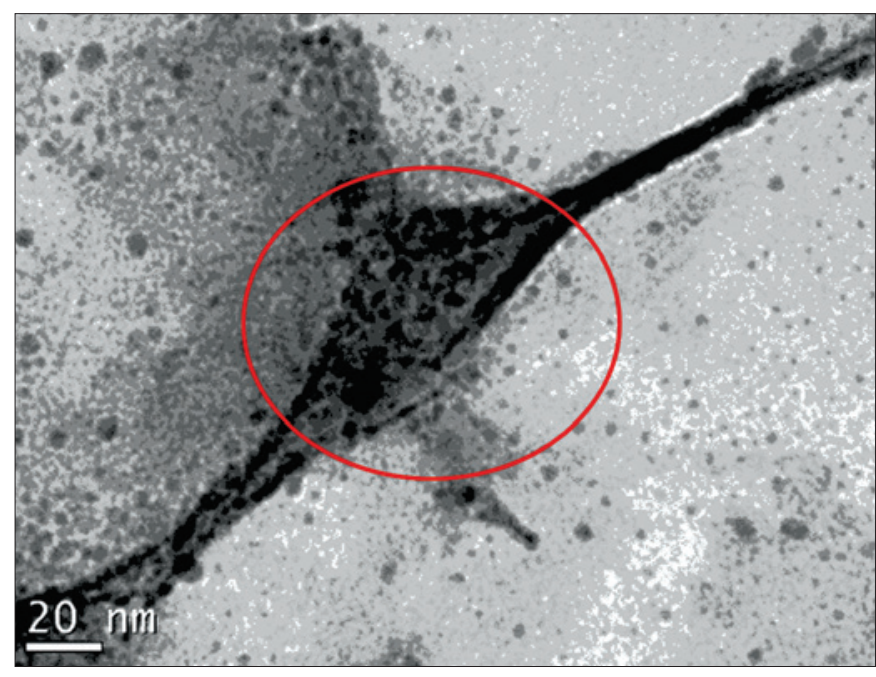

(a)

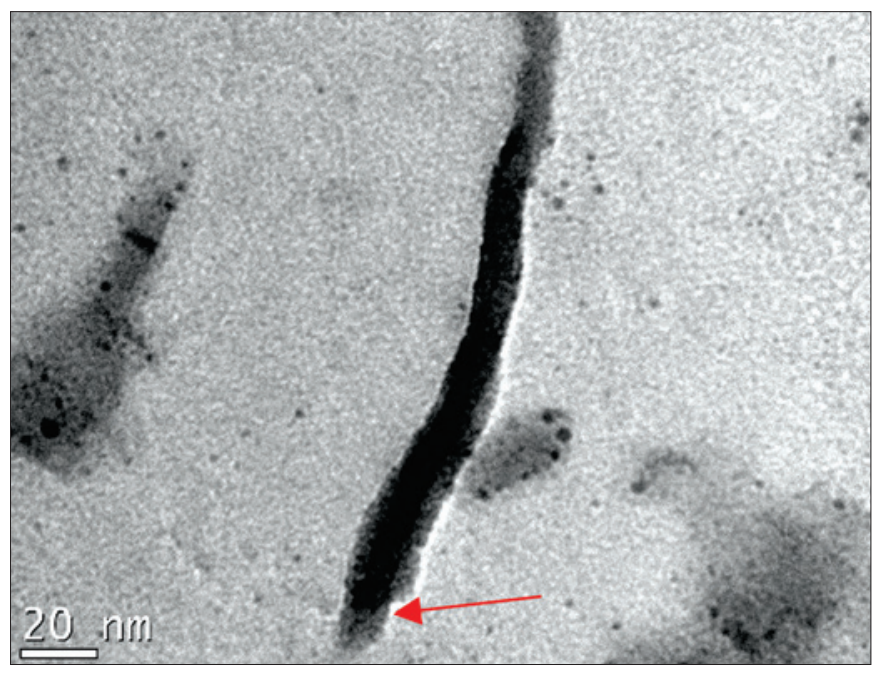

(b)

\section{Figure 7}

TEM micrographs of CNT sonicated under: (a) $80 \%$ amplitude for $60 \mathrm{~min}(6480 \mathrm{~J} / \mathrm{ml}$ ) and (b) $50 \%$ amplitude for $30 \mathrm{~min}(1620 \mathrm{~J} / \mathrm{ml})$ 

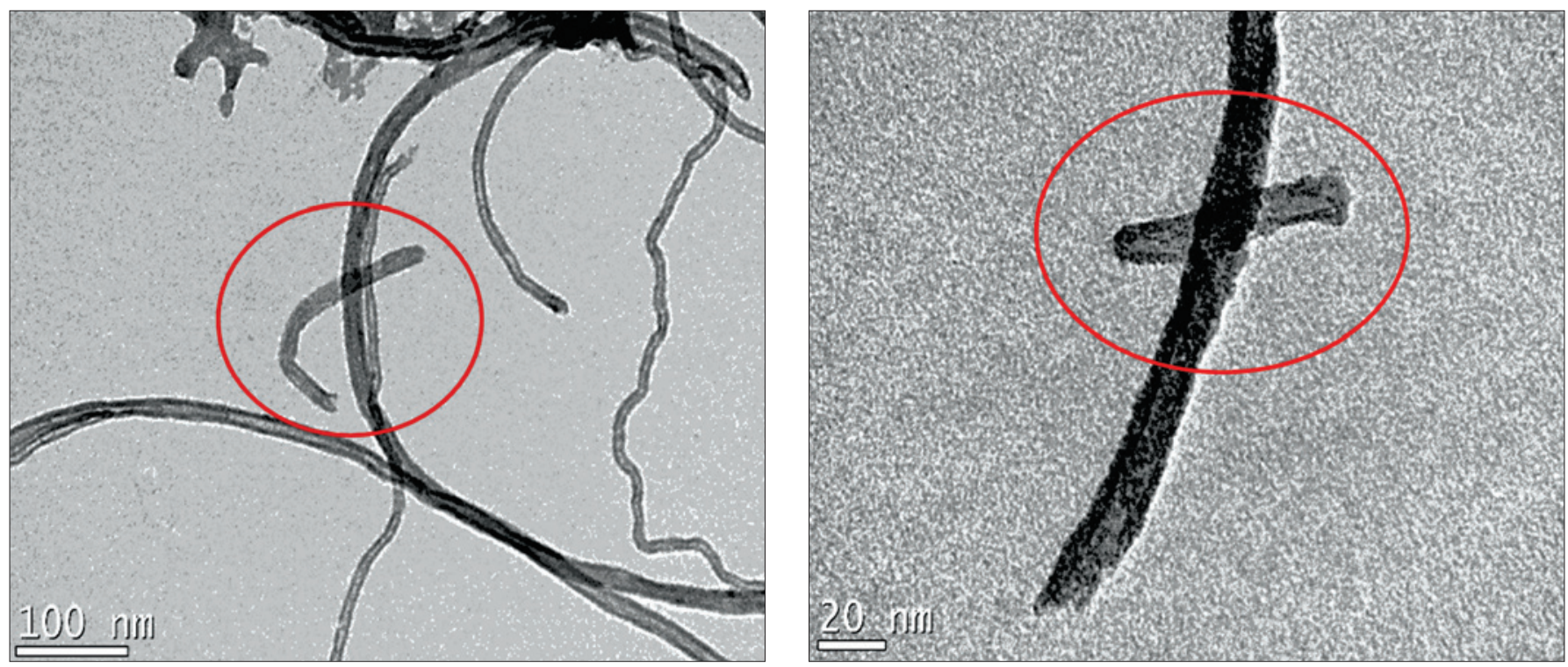

Figure 8

TEM micrographs of CNTs sonicated under the amplitude of $80 \%$ over 6 min $(648 \mathrm{~J} / \mathrm{ml})$

In the case of high sonication amplitude over a short period of time ( $80 \%$ over 6 min; FIGURE 8), the CNT morphology appears to remain unchanged from its original form. However, a few very short CNTs with intact walls are also observed, which are probably cut off from other CNTs as reported in a previous research [9].

TABLE 3 summarizes the qualitative evaluation by TEM of the CNTs integrity after sonication.

\subsection{Cement composites}

Considering the highest dispersion behavior measured with UV-Vis absorbance, the physical-mechanical tests of cement composites were carried out only with the formulations in which the SP admixture was sonicated with CNTs.

\subsubsection{Mini-slump test}

Mini-slump measurements clearly reveal that as CNTs suspensions sonication amplitude, time and consequently sonication energy (fig. 9) increase, cement paste workability decreases. The pastes with low CNTs suspension sonication energy $(<500 \mathrm{~J} / \mathrm{ml}$ ) exhibit similar workability than that of the reference paste (RP -

\section{Table 3}

TEM observations of the CNT integrity after sonication

\begin{tabular}{|c|c|c|c|}
\hline $\begin{array}{l}\text { Sonication } \\
\text { conditions }\end{array}$ & $\begin{array}{c}80 \%-60^{\prime} \\
6480 \mathrm{~J} / \mathrm{ml} \\
\end{array}$ & $\begin{array}{c}50 \%-30^{\prime} \\
1620 \mathrm{~J} / \mathrm{ml}\end{array}$ & $\begin{array}{c}80 \%-6^{\prime} \\
648 \mathrm{~J} / \mathrm{ml}\end{array}$ \\
\hline $\begin{array}{l}\text { CNT wall } \\
\text { damage }\end{array}$ & Severe & Low & Inexistent \\
\hline $\begin{array}{l}\text { CNT diameter } \\
\text { reduction }\end{array}$ & High & High & Low \\
\hline CNT cutting & High & High & Medium \\
\hline
\end{tabular}

without sonication). However, high sonication energy (> $1500 \mathrm{~J} / \mathrm{ml}$ ) induces severe workability decrease.

It is considered that high energy CNT suspension sonication causes the breaking of CNTs into smaller pieces, as was observed by TEM. This results in an increase in the quantity of CNTs and the quantity of SP adsorbed by them. Thus, less SP is available to disperse cement particles and, consequently, workability decreases.

\subsubsection{Compressive and flexural strength}

FIGURE 10 clearly reveals that for low sonication energy $(<1000$ $\mathrm{J} / \mathrm{ml}$ ), the compressive strengths of the cement-CNTs pastes are higher than that of the reference paste, attaining a $10 \%$ increase for the CNTs suspensions subjected to $80 \%$ amplitude and 6 min. sonication. It is also evident that longer sonication periods nega-

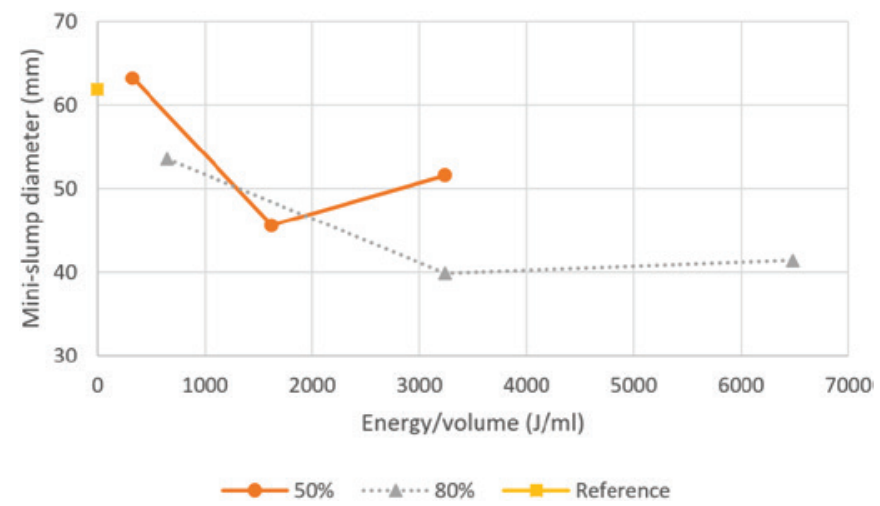

\section{Figure 9}

Consistency (mini-slump diameters) vs CNT suspension sonication energy 


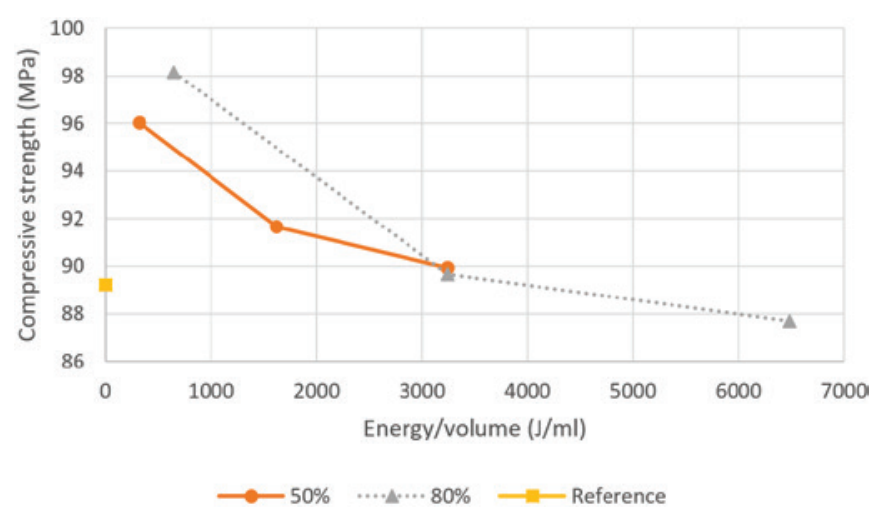

Figure 10

Cement-CNTs paste compressive strength vs CNTs suspensions sonication energy

tively affect the compressive strengths of cement-CNTs pastes. A similar tendency can be observed for flexural strength measurements (FIGURE 11). However, the gain is higher (up to $30 \%$ for $80 \%$ amplitude and 6 min. sonication). In addition, as observed for compressive strength, as the CNTs suspension sonication energy increases, the flexural strengths of the cement-CNTs pastes decrease.

In the case of low sonication energy, the increase in the cement pastes' compressive (10\%) and flexural $(30 \%)$ strengths was very similar to the results of other researches with low CNTs ratio (approximately $0.1 \%$ wt cement) [2, 30, 31, 32].

According to Konsta-Gdoutos, Metaxa, and Shah [2], the key factor for improving the strength of a cement matrix is the effective dispersion of the CNTs. It results in the reduction of the CNT-free area in the material and in an increase in the mechanical performance of the nanocomposite.

However, there was a significant decrease in the cement pastes strength values with increase in the sonication energy.

As observed by TEM, high sonication energy results in CNTs wall damage, diameter reduction and cutting; consequently, its strength was reduced, and UV-Vis spectroscopy revealed that higher dispersion was not achieved. Hence, the reinforcing role of CNTs is

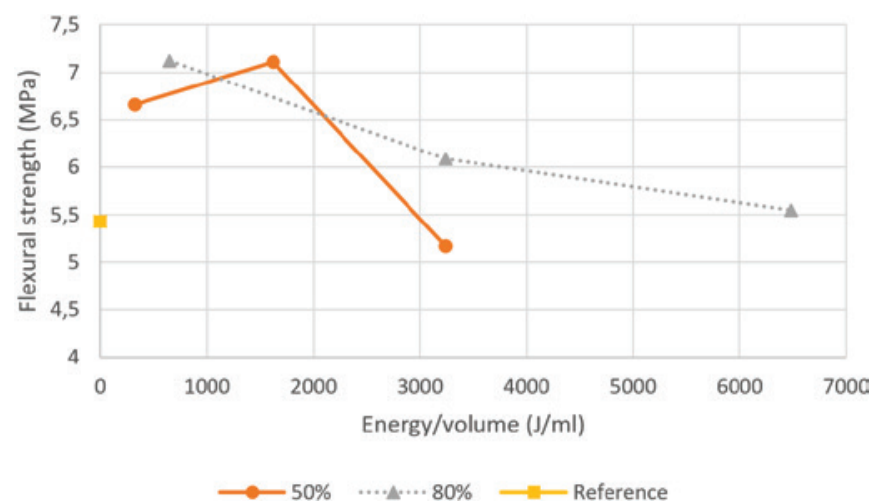

Figure 11

Cement-CNTs pastes flexural strength

vs CNTs suspensions sonication energy likely to be reduced. Moreover, as mentioned earlier, the "destruction" of the CNTs by high sonication energy is likely to increase its specific surface, which increases its SP adsorption and thus, reduces cement paste workability; this is likely to cause the incorporation of voids and failure in specimen molding, resulting in a decrease in the mechanical performances [19].

Isfahani, Li and Redaelli [21] suggested that water suspensions with highly dispersed CNTs do not necessarily result in high CNTs dispersion in the cement matrix. Re-agglomeration can be caused by the contact between the CNTs surface and the solid phase (cement particles) during the mixing procedure. Thus, both CNTs agglomeration and the damage to CNTs by sonication, can reduce the reinforcement capability of the nanomaterials.

However, Isfahani, Li and Redaelli [21] demonstrated that the increase in CNTs sonication energy did not result in significant gain or loss of strength of the cement composites. These results are different compared with the present research, wherein a gain in the cement composites' strengths was observed with lower sonication energies (high amplitude for a short time) and a decrease in these properties was observed with higher sonication energies (high amplitude for a long time).

\section{Conclusions}

The main conclusions of this work are as follows:

1. The dispersion of CNTs in aqueous solution is proportional to the sonication energy used, until a determinate energy value;

2. The presence of the superplasticizer admixture with the CNTs in the water during the sonication process is essential for an effective dispersion;

3. The use of high sonication energy for a long period results in the breaking of the CNTs walls and a significant reduction in diameter and length;

4. When high energy is applied for short periods, no CNTs damage was observed;

5. The CNTs cement pastes' workability is inversely proportional to the sonication energy of the CNTs suspensions. It is considered that under high sonication energy, there is higher dispersion of shorter nanotubes (cut by sonication) in the paste and/ or a larger adsorption of the SP on the CNT, which results in a significant increase in its cohesion and a lesser availability of SP for dispersing the cement;

6. Concerning the CNTs pastes' mechanical behavior, it was observed a significant increase in the compressive and flexural strengths (up to 10 and $30 \%$ respectively) for low sonication energies (less than $1000 \mathrm{~J} / \mathrm{ml}$ ). For higher sonication energies, the pastes' compressive and flexural strengths decrease mainly owing to the higher cohesion of the pastes and the consequent higher difficulty of molding, the incorporation of empty spaces, and/or the higher damages suffered by the CNTs;

7. As an overall conclusion, it was demonstrated that the sonication parameters of CNTs suspensions can be optimized in order to enhance the CNT-cement paste behavior.

\section{Acknowledgments}

The authors gratefully acknowledge the Brazilian research agencies National Council for Scientific and Technological Development 
(CNPq) and Santa Catarina Research Foundation (FAPESC) for providing the financial support for this research and the Coordination for the Improvement of Higher Education Personnel (CAPES) for providing scholarships to the first author.

\section{References}

[1] Yu M, Files BS, Arepalli S, Ruoff RS. Tensile loading of ropes of single wall carbon nanotubes and their mechanical properties. Physical review letters, v. 84 , n. 24, 2000 p. $5552-5555$.

[2] Konsta-Gdoutos MS Metaxa ZS, Shah SP. Highly dispersed carbon nanotube reinforced cement based materials. Cement and Concrete Research, v. 40, 2010; p. 1052-1059.

[3] Parveen S, Raba S, Fangueiro R. A review on nanomaterial dispersion, microstructure and mechanical properties of carbon nanotube and nanofiber reinforced cementitious composites. Journal of Nanomaterials, v. 2013, 2013; $19 \mathrm{p}$

[4] Yakovlev G, Pervushin G, Maeva I, Keriene J, Pudov I, Shaybadullina A, Buryanov A, Korzhenko A, Senkov S. Modification of construction materials with multi-walled carbon nanotubes. Procedia Engineering, v. 57, 2013; p. 407-413.

[5] Paula JN, Calixto JM, Ladeira LO, Ludvig P, Souza TCC, Rocha JM, Melo AAV. Mechanical and rheological behavior of oil-well cement slurries produced with clinker containing carbon nanotubes. Journal of Petroleum Science and Engineering, v. 122, 2014; p. 274-279.

[6] Wang B, Guo Z, Han Y, Zhang T. Electromagnetic wave absorbing properties of multi-walled carbon nanotube/cement composites. Construction and Building Materials, v. 46, 2013; p. 98-103.

[7] Han B, Sun S, Ding S, Zhang L, Yu X, Ou J. Review of nanocarbon-engineered multifunctional cementitious composites. Composites: Part A, v. 70, 2015; p. 69-81.

[8] Ma P, Siddiqui NA, Marom G, Kim J. Dispersion and functionalization of carbon nanotubes for polymerbased nanocomposites. Composites: Part A, v. 41, 2010; p. $1345-1367$.

[9] Chen SJ, Zou B, Collins F, Zhao XL, Majumber M, Duan $\mathrm{WH}$. Predicting the influence of ultrasonication energy on the reinforcing efficiency of carbon nanotubes. Carbon, v. 77, 2014; p. 1-10.

[10] Mendoza O, Sierra G, Tobón JI. Influence of super plasticizer and $\mathrm{Ca}(\mathrm{OH})_{2}$ on the stability of functionalized multiwalled carbon nanotubes dispersions for cement composites applications. Construction and Building Materials, v. 54,2014 ; p. 550-557.

[11] Carlesso DM. Avaliação do desempenho do aditivo superplastificante de base policarboxilato pré-tratado por sonicação na dispersão de pastas de cimento. Universidade Federal de Santa Catarina, Florianópolis, Brazil, Masters Dissertation. 2015, p. 135.

[12] Rastogi R, Kaushal R, Tripathi SK, Sharma AL, Kaur I, Bharadwaj LM. Comparative study of carbon nanotube dispersion using surfactants. Journal of Colloid and Interface Science, v. 328, 2008; p. 421-428.

[13] Shah SP, Konsta-Gdoutos MS, Metaxa ZS, Mondal P. Nanoscale modification of cementitious materials. In: Bittnar Z, Bartos PJM, Nemecek J, Smilauer V, Zeman J. Nanotechnology in construction - 3. Proc. NICOM3. Praga: Springer Press, 2009, p. 125-130.

[14] Rausch J, Zhuang R-C, Mäder E. Surfactant assisted dispersion of functionalized multi-walled carbon nanotubes in aqueous media. Composites: Part A, v. 41, 2010; p. 1038-1046.

[15] Blanch AJ, Lenehen CE, Quinton JS. Parametric analysis of sonication and centrifugation variables for dispersion of single walled carbon nanotubes in aqueous solutions of sodium dodecylbenzene sulfonate. Carbon, v. 49, 2011; p. $5213-5228$.

[16] Metaxa ZS, Seo JT, Konsta-Gdoutos MS, Hersam MC, Shah SP. Highly concentrated carbon nanotube admixture for reinforced cementitious materials. Cement \& Concrete Composites, v. 36, 2013; p. 25-32.

[17] Al-Rub RK, Ashour Al, Tyson BM. On the aspect ratio effect of multi-walled carbon nanotube reinforcements on the mechanical properties of cementitious nanocomposites. Construction and Building Materials, v. 35, 2012; p. 647-655.

[18] Sobolkina A, Mechtcherine V, Khavrus V, Maier D, Mende $M$, Ritschel M, Leonhardt A. Dispersion of carbon nanotubes and its influence on the mechanical properties of the cement matrix. Cement \& Concrete Composites, v. 34, 2012; p. 1104-1113.

[19] Collins F, Lambert J, Duan WH. The influences on the dispersion, workability and strength of carbon nanotubeOPC paste mixtures. Cement \& Concrete Composites, v. 34, 2012; p. 201-207.

[20] Zou B, Chen SJ, Korayem AH, Collins F, Wang CM, Duan $\mathrm{WH}$. Effect of ultrasonication energy on engineering properties of carbon nanotube reinforced cement pastes. Carbon, v. 85, 2015; p. 212-220.

[21] Isfahani FT, Li W, Redaelli E. Dispersion of multi-walled carbon nanotubes and its effects on the properties of cement composites. Cement \& Concrete Composites, v. 74, 2016; p. 154-163.

[22] Stynoski P, Mondal P, Wotring E, Marsh C. Characterization of silica-functionalized carbon nanotubes dispersed in water. Journal of Nanoparticle Research, v. 15, n. 1396, 2013; 10p.

[23] Jiang L, Gao L, Sun J. Production of aqueous colloidal dispersions of carbon nanotubes. Journal of Colloid and Interface Science, v. 260, 2003; p. 89-94.

[24] Grossiord N, Regev O, Loos J, Meuldjik J, Koning CE. Time-dependent study of the exfoliation process of carbon nanotubes in aqueous dispersions by using UV-Visible Spectroscopy. Analytical Chemistry, v. 77, n. 16, 2005; p. 5135-5139.

[25] Yu J, Grossiord N, Koning CE, Loos J. Controlling the dispersion of multi-wall carbon nanotubes in aqueous surfactant solution. Carbon, v. 45, 2007; p. 618-623. 
[26] Yu H, Hermann S, Schulz SE, Gessner T, Dong Z, Li WJ. Optimizing sonication parameters for dispersion of single-walled carbon nanotubes. Chemical Physics, v. 408, 2012; p. 11-16.

[27] Alafogianni P, Dassios K, Farmaki S, Antiohos SK, Matikas TE, Barkoula N-M. On the efficiency of UV-Vis spectroscopy in assessing the dispersion quality in sonicated aqueous suspensions of carbon nanotubes. Colloids and Surfaces A: Physicochemical and Engineering Aspects, v. 495, 2016; p. 118-124.

[28] George N, Bipinbal PK, Bhadran B, Mathiazhagan A, Joseph R. Segregated network formation of multiwalled carbon nanotubes in natural rubber through surfactant assisted latex compounding: A novel technique for multifunctional properties. Polymer, v. 112, 2017; p. 264-277.

[29] Strano MS, Moore VC, Miller MK, Allen MJ, Haroz CK, Hauge RH, Smalley RE. The role of surfactant adsorption during ultrasonication in the dispersion of single-walled carbon nanotubes. Journal of Nanoscience and Nanotechnology, v. 3, 2003; p. 81-86.

[30] Bharj J, Singh S, Chander S, Singh R. Experimental study of Cement-CNT composite paste. Indian Journal of Pure and Applied Physics, v. 52(1), 2014; p. 35-38.

[31] Cwirzen A, Habermehl-Cwirzen K, Penttala V. Surface decoration of carbon nanotubes and mechanical properties of cement/carbon nanotubes composites. Advances in Cement Research, v. 20, n. 2, 2008; p. 65-73.

[32] Xu S, Liu J, Li Q. Mechanical properties and microstructure of multi-walled carbon nanotube-reinforced cement paste. Construction and Building Materials, v. 76, 2015; p. 16-23. 